\title{
New Findings for Face Processing Deficits in the Mental Disorder of Schizophrenia
}

\author{
Toshiaki Onitsuka ${ }^{1}$, Tomoya Tsunoda ${ }^{1,2}$ and Naotoshi Ohara ${ }^{1}$ \\ ${ }^{1}$ Department of Neuropsychiatry, Graduate School of Medical Sciences, \\ Kyushu University \\ 2Department of Neuropsychiatry, Self-Defense Forces Sasebo Hospital
}

Japan

\section{Introduction}

Human faces may be one of the most familiar visual stimuli, and the most important stimulus for human social life. The highly evolved human ability to recognize faces represents an important component of species social communication, naturally selected to solve adaptive problems critical for survival, such as distinguishing friend from foe, familiar from unfamiliar, related from unrelated. Moreover, face recognition represents an evolutionarily significant element of nonverbal decoding that may be viewed as a neuropsychological building block for sociality that is a core ingredient of extraversion. Indeed, a critical component of the kind of effective nonverbal decoding seen in extraverts may presuppose a capacity to extract social and affective cues from faces. Face recognition may be qualitatively different from other memory recognition systems in terms of the underlying neurobiological structure and developmental trajectory. It has been suggested that a special brain processing network, present early in development, underlies face perception. For example, two-month-old infants recognize their mothers' faces among others (Morton \& Johnson, 1991), showing that infants have the perceptual skill of eye gaze from birth (Farroni et al., 2002). These studies suggest that face recognition is formed in the first few months of life. Face recognition includes many processes (perception of the face configuration, retention, memorization, and verification of face images). There has been uniform agreement that the facial recognition processes involves multiple brain areas.

In the last several decades, methods of cognitive neuroscience have been applied fruitfully to the study the cognitive deficits in schizophrenia; however, the studies of the processes for facial recognition and recognition of facial expressions have received less attention. Recently, application of neuroscience techniques, including electroencephalography (EEG), magnetoencephalography (MEG), and structural and functional magnetic resonance imaging (MRI) to the study of face recognition has produced a new field of neuroscience. Therefore, abnormalities in the face recognition processes associated with psychiatric diseases have been revealed using these techniques.

This chapter first presents an overview of the recent findings from studies on the neuronal mechanisms of face recognition, based on the current theoretical models. Second, the findings on abnormalities of facial recognition in patients with schizophrenia will be reviewed. 


\section{Face-responsive brain regions}

Research to investigate the direct neuronal activities of face recognition require invasive procedures, so most studies have been investigated by examining monkey brains. Hasselmo et al. (1989) reported that the superior temporal sulcus (STS) and the inferior temporal gyrus (ITG) in monkeys contain neurons which responded only to a picture of human or monkey faces. Neurons in the STS analyze mainly the changeable aspects of faces; the emotional expression (Perrett et al., 1984), eye gaze (Eifuku et al., 2004), and mimicry (Oram \& Perrett, 1996). The ITG seems to be the site for storage of static features of faces (Hasselmo et al., 1989; Perrett et al., 1984, 1985). The amygdala is involved in emotional perception and regulation, and production of emotional feelings (Nakamura et al., 1992). In addition, several other brain regions are involved in face recognition. The region of the orbitofrontal cortex and the vicinity are activated by faces for longer durations and with lower activation compared to the temporal lobes (Thorpe et al., 1983; Rolls et al., 2006; Wilson et al., 1993). The section below presents an overview of each region related to face recognition.

\subsection{Fusiform gyrus}

A key brain region of the network for face recognition is the fusiform gyrus (FG) (Allison et al., 1999; Damasio et al., 1982; Kanwisher et al., 1997), which is located on the ventromedial surface of the temporal and occipital lobes (see Figure 1). The FG is bordered medially by the collateral sulcus and laterally by the occipitotemporal sulcus; both of the sulci are frequently interrupted with bifurcations, particularly in the anterior and posterior part of the FG (Naidich et al., 1987; Ono et al., 1990).

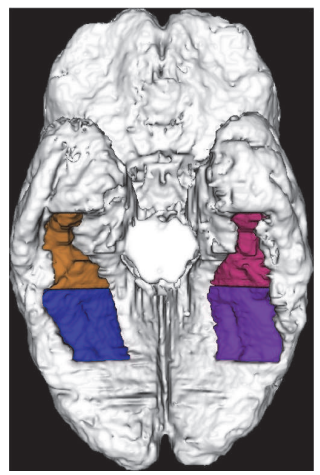

Fig. 1. Ventral view of a three-dimensional reconstruction of the FG.

The gray matter of the anterior fusiform gyrus is shown in red (left subject) and orange (right subject). The gray matter of the posterior fusiform gyrus is shown in purple (left subject) and blue (right subject).

Although both face and non-face object perception use the ventral pathway (Martin et al., 2001), EEG, MEG and fMRI studies have reported that faces are perceived, at least in part, by a separate processing stream in the ventral pathway (Allison et al., 1999; Kanwisher et al., 1997; Watanabe et al., 1999). Using fMRI, Kanwisher et al. (1997) reported that the middle portion of the FG responded predominantly to faces, leading them to call it the fusiform face area (FFA). Many studies have supported that the FFA is more active when stimuli have 
been detected as faces. The most robust face-sensitive activation is consistently found on the lateral side of the right middle portion of the FG (Kanwisher et al., 1997). Additionally, the FFA responds to a wide variety of face stimuli; front and profile photographs of faces (Tong et al., 2000), line drawings of faces (Spiridon et al., 2002), animal faces (Chao et al., 1999b; Tong et al., 2000) and even faces of cartoon characters (Tong et al., 2000). Although the FFA shows the strongest increase in blood flow in response to faces, it also responds to non-face stimuli, such as houses (Aguirre et al., 1998; Ishai et al., 1999), chairs (Ishai et al., 1999), tools (Chao et al., 1999a), landscapes (Epstein et al., 1998) or nonsense stimuli (Clark et al., 1996; Epstein et al., 1998). Some fMRI studies suggest that the right FFA, also associated with face perception, can also be recruited in the processing of objects that subjects are highly familiar with, as in cases of expert knowledge for objects (Gauthier et al., 1999, 2001). Indeed, similar EEG responses to faces and, after repeated training, to other objects, have been reported (Tanaka et al., 2001; Rossion et al., 2002). This observation has led to the suggestion that functional and anatomical specialization for faces in healthy adults could simply reflect our extensive experience with human faces (Gauthier et al., 2001). An important assumption of the expertise hypothesis is that object expertise can be developed entirely as an adult, and the predictor of processing style is merely the amount of practice. This assumption has remained implicit in subsequent research (Gauthier et al., 1997; Grill-Spector et al., 2004; Rossion et al., 2002).

\subsection{Superior temporal sulcus region}

The STS is the sulcus separating the superior temporal gyrus (STG) from the middle temporal gyrus (MTG) in the temporal lobe of the brain (see Figure 2). The STS is frequently interrupted (the proportion of STS that have a single continuous sulcus is $36 \%$ for the right side and $28 \%$ for the left side), and the posterior part of the STS is extremely varied (Ono et al., 1990). For face processing by the STS, Kanwisher et al. (1997) reported that the superior and lateral regions of the right STS were significantly activated, as observed using fMRI, when the subjects viewed faces. Although the STS is generally involved in the perception of biological motion (Bonda et al., 1996; Decety et al., 1999; Grossman et al., 2000), for face recognition, the STS is also activated by mimics of faces. The STS responds to dynamic aspects of faces beyond gaze shifts (Calder et al., 2002), including lip movements (Puce et al., 1998) and emotion expression (Narumoto et al., 2001) as well as complex social cues such as trustworthiness (Winston et al., 2002). Moreover, it has been reported that the changeable aspects of faces are processed by a second face-specific processor located in the posterior part of the STS (Chao et al., 1999; Haxby et al., 1999; Hoffman \& Haxby, 2000; Puce et al., 2007). For instance, Hooker et al. (2003) reported that STS activity accompanied extracting directional information from a gaze relative to directional information from an arrow and relative to eye motion without relevant directional information. In this study, subjects attempted to detect a particular directional cue provided either by gaze changes on an image of a face or by an arrow presented alone or by an arrow superimposed on the face. Another control condition was included in which the eyes moved without providing meaningful directional information. Moreover, Hoffman and Haxby (2000) reported that activation of the STS depended on the aspects of the face upon which attention was focused. In their results, the activity in the STS region was significantly higher when subjects were paying attention to the changeable aspects of the face than in the invariant condition. Such selectivity for gaze processing was observed only in the STS, but not in the FG. 


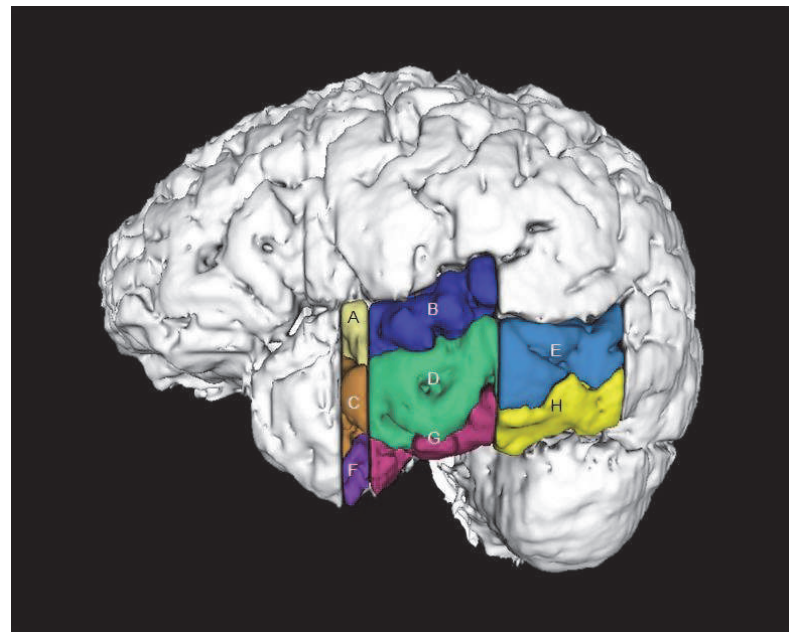

Fig. 2. STG, MTG, and ITG in the left hemisphere on a three-dimensional image. A: anterior STG, B: posterior STG, C: anterior MTG, D: mid- MTG, E: posterior MTG, F: anterior ITG, G: mid- ITG, H: posterior ITG.

\subsection{Inferior occipital gyrus (Occipital face area: OFA)}

In addition to the FG and the STS, the lateral inferior occipital gyrus is one of the faceresponsive regions (Adolphs, 2003; Halgren et al., 1999). The FG and the STS are responsible for preliminary face analysis according to the Haxby model (Haxby et al., 1999, 2000), and it is suggested that the OFA may glean more significant information from faces compared to both the FG and the STS (Haxby et al., 1999; Hoffman \& Haxby, 2000). However, the OFA is activated by tasks in which the FFA is activated, thus suggesting that the OFA is also involved in processing the identity of faces (Hoffman \& Haxby, 2000).

\subsection{Other regions}

Many research studies have shown that there are other regions engaged in face perception; the anterior portion of the middle temporal gyrus (aMTG) (see Figure 2), the orbitofrontal cortex (Nakamura et al., 2000; Sergent et al., 1992) and the right ventrolateral prefrontal cortex (Marinkovic et al., 2000; Vignal et al., 2000). The aMTG and the orbitofrontal cortex show both show a high activity when faces of famous or familiar persons are viewed. Studies with epilepsy patients also revealed the role of the right ventrolateral prefrontal cortex relevant to face processing.

The amygdala also participates in face recognition. The amygdala is an almond-shaped nucleus located deep within the medial temporal lobes of the brain in complex vertebrates. The amygdala has a primary role in the processing and memory of emotional reactions, and it is considered to be part of the limbic system. Actually, the recognition of emotions elicited a stronger response than neutral face detection. The activation occurs first in the STS (140$170 \mathrm{~ms}$ after the stimulus onset) and later in the right amygdala (around $220 \mathrm{~ms}$ after the stimulus onset) (Streit et al., 1999). Moreover, it has been reported that the amygdala plays a crucial role in processing fear (LaBar et al., 1998; Morris et al., 1998). Subsequent studies also showed activation of the amygdala in response to a happy face (Sheline et al., 2001) as well 
as negative emotional faces like those expressing fear, sadness, anger (Blair et al., 1999) and disgust (Gorno-Tempini et al., 2001).

Additional regions in other parts of the brain also participate in face perception. For example, lip-reading elicits activity in regions associated with auditory processing of speech sounds (Calvert et al., 1997) and the perception of eye gaze direction elicits activity in parietal regions that are associated with spatial attention (Hoffman \& Haxby, 2000).

\section{Face recognition systems}

Bruce and Young proposed a model of distributed face processing in humans (Bruce \& Young, 1986). The essences of their model are that face perception differs qualitatively from the perception of other objects or words, and there may be several modules that independently process face information in human brain. Each face stimulates seven distinct types of mental processing; pictorial, structural, visually derived semantic, identity-specific semantic, name, expression and facial speech. According to this model, face perception processing consists of a four stage process; the first-stage being structural encoding to provide descriptions suitable for the analysis of facial speech, for the analysis of expression and for face recognition units; the second-stage being recognition of familiar faces, which involves a match between the products of structural encoding and previously stored structural codes describing the appearance of familiar faces; the third-stage is identification of specific semantic codes accessed from person identity nodes; and in the fourth-stage, name codes are retrieved.

Haxby et al. (2000) postulated a face processing model mediated by distributed neural systems in the human brain with core and extended systems. The core system is composed of regions in the visual cortex (inferior occipital cortex, FG, STS), which modulate the visual analysis of faces. In their model, the extended system of neural networks is as follows; intraparietal sulcus, auditory cortex, amygdala, insula, limbic system, and temporal pole.

Both models postulate multistage processing of face information and separate means of face analysis. Although these models do not take into account the attention effect, unconscious face processing is also important for face perception. With regard to this point, Bauer suggested a two-route model (Bauer, 1984), which was later developed by Ellis and Young (1990). Bauer reported that the skin conductance response was highly sensitive to the presentation of familiar faces in patients with prosopagnosia despite their inability to recognize familiar faces due to damage to the inferior temporal lobes (Bauer, 1984). Therefore, Bauer concluded that visual information processing remained partially separate from conscious face processing. The human brain has two neural visual pathways for the analysis of face information, both being directly connected with the limbic system. First, the ventral stream is responsible for overt face recognition. It starts at the visual association cortex and continues via the inferior temporal lobes to the amygdala and hypothalamus. The ventral stream, sometimes called the "what pathway", is associated with configuration recognition and object representation. Second, the dorsal stream is responsible for the covert analysis of facial stimuli. This pathway starts at the visual association cortex and comprises the superior temporal and inferior parietal lobes, the cingulate gyrus and the hypothalamus. The dorsal stream is sometimes called the "where pathway" or "how pathway". Bauer's model may account for the face recognition deficits accompanying some other disorders such as Capgras syndrome (Ellis \& Young, 1990), unilateral spatial neglect (Vuilleumier, 2000) and the blind sight phenomenon (Morris et al., 1998). 


\section{Prosopagnosia}

Neuropsychological studies have reported a number of brain-damaged patients who exhibited a disproportionate impairment for recognizing faces as compared to other objects. Especially, prosopagnosia has been crucial in the development of theories of face recognition. Prosopagnosia is one of the disorders of face perception, usually associated with bilateral or right unilateral occipito-temporal lesions (Damasio et al., 1982; Farah, 1991; Landis et al., 1988; Wada \& Yamamoto, 2001). For example, Wada and Yamamoto (2001) reported a case of prosopagnosia caused by a hematoma limited to the right FG and to the lateral occipital region.

The word "prosopagnosia" derives from the Greek prosopon (face) and gnosis (knowledge), which was introduced by Bodamer (1947). Damasio et al. (2000) described that the deficit of prosopagnosia is not limited to human faces. The magnitude of the deficit of visual agnosia varies in prosopagnosia; a farmer cannot recognize his cows individually and a birdwatcher cannot identify different species of birds. According to their description (Damasio et al., 2000), patients with prosopagnosia can recognize a pencil, or an article of furniture, or a car, as, respectively, pencils, furniture, and cars; but they often cannot decide whether such an article belongs to them or not, or who the specific manufacturer of a given car is. Although dysfunction of the FG produces difficulties in identifying a face, patients with prosopagnosia can recognize facial expressions (Morris et al., 2001). The dissociation between recognizing a face and a facial expression may be associated with the tectopulvinar system, which processes facial expression perception. Thus, patients with prosopagnosia can recognize a face implicitly because of emotional responses to facial expressions even if they are not perceived consciously. This suggests that emotion also plays a significant role in face recognition, as a relatively independent module.

\section{The face-related potentials}

The evidence regarding face recognition comes from two very different methodologies, neuroimaging and neurophysiology. Face processing also can be assessed by metabolic activity, blood deoxygenation, and glucose uptake in the human brain (Haxby \& Gobbini, 2002; Henson et al., 2003). Metabolic brain imaging techniques produce information about the regions that are related to the face recognition processes. Meanwhile, neurophysiological studies, including EEG and MEG, have revealed the individual regions associated with human face processing with a high temporal resolution.

Of particular note, numerous EEG studies, especially event-related potentials (ERP) studies have revealed the presence of face-sensitive potentials are absent or attenuated to non-face visual stimuli (Jeffreys, 1989). ERPs are measures of neurophysiological activity, and represents a non-invasive method used to clarify the time course of visual object categorization processes in the human brain. Artifact-free EEG segments time-locked to stimuli onsets have been averaged over many trials, revealing the timing and magnitude of consistent neural processing elicited by stimuli. Data from ERP studies have demonstrated the negative potential recorded at occipitotemporal leads, the N170, to be larger for faces than objects in humans (Bentin et al., 1996; Botzel et al., 1995; Rossion et al., 2000). For MEG, the magnetic counterpart of N170 (M170) to the face is also larger for faces than objects (e.g., Lu et al., 1991). 
There is a face-sensitive potential with a maximum amplitude and minimum latency to faces than other objects at vertex electrodes, called vertex positive potentials (VPP) (Botzel \& Grusser, 1989; Jeffreys, 1989). It has been reported that the VPP represents the positive counterpart of the N170 (Botzel et al., 1995).

Intracranial ERP recordings of epilepsy patients have also found face-sensitive N200, which were recorded from both hemispheres of the FG and the ITG (Allison et al., 1994, 1999). Several discrepancies have been reported between the scalp N170 and intracranial N200. For example, the intracranial face-N200 showed no hemispheric asymmetry, whereas rightgreater-than-left scalp face-N170 amplitudes have been frequently demonstrated (Henson et al., 2003; Itier \& Taylor, 2004). The scalp N170 generally corresponds to the intracranial N200, but the N170 may be an overlapping potential and, therefore, the N170 is not exactly the same as the N200.

\section{Evaluation of face processing}

As emotionally expressive stimuli, faces can bridge multiple levels of the emotional response. Faces can be classified as showing positive and negative emotions. In addition, faces also express categorical emotions. The universality of facial expressions that communicate anger, disgust, fear, happiness, sadness, and surprise is widely accepted (Ekman, 1994; Izard, 1994). Subjects tend to mistake fear and surprise, disgust and anger, and neutrality and sadness (Ekman, 1972; Gur et al., 2002). Most facial expression research is done with static, posed images (Edwards et al., 2002); however, naturally elicited expressions will change within milliseconds and there are differences in the way in which some subjects respond to posed vs. natural expressions (Davis \& Gibson, 2000). This section will focus on the neuropsychological findings for processing of static images of emotional faces. It should also be noted that most studies used their own original emotional face recognition tests. For example, one research group has worked extensively with emotional face processing. The Penn Emotion Acuity Test (PEAT) (Kohler et al., 2000) consists of 10 happy, $10 \mathrm{sad}$, and 20 neutral expressions of Caucasian faces. The task requires the participant to indicate the emotion depicted on a 7-point Likert-type intensity scale $(1=$ very sad, 2 = moderately sad, $3=$ somewhat sad, $4=$ neutral, $5=$ somewhat happy, $6=$ moderately happy, 7 = very happy). The Emotion Intensity Differentiation task (Emodiff) presents two faces of the same individual showing the same emotion (happy or sad), requiring the participant to select the more intense expression. A total of 40 face pairs (20 happy, $20 \mathrm{sad}$ ) are used in this study (Silver et al., 2002). However, various tests are used to assess the recognition of emotional faces in reading the following sections.

Although threatening stimuli, including faces, are detected more rapidly in visual search tasks, studies that emphasize identification of expressions, rather than detection of differences, commonly find that happy faces elicit faster response times than other expressions (Leppanen \& Hietanen, 2004). Happy faces are also widely found to be identified more accurately (e.g., Gur et al., 2002). Both of these effects could be due to structural aspects of the expressions as visual stimuli, rather than the affective meaning itself. Happy expressions are of a very different structural conformation and rely more on visual analysis of the mouth area and less on the eye areas than negative expressions (sadness, fear, anger; [Ekman \& Friesen, 1978; Smith et al., 2003]). 


\section{Behavioral studies for face recognition in schizophrenia}

Recently, interest in the neural physiology of emotional processing in schizophrenic patients has undergone a resurgence. Impaired emotional functioning is fundamental to schizophrenia, and negative symptoms, including flat affect, are debilitating and resistant to intervention. These emotional impairments include deficits in how emotional meaning is assigned to incoming sense data, how emotions are felt and elicited by life circumstances (e.g., inappropriate affect, persecutory delusions), and how emotions are encoded and transmitted during communication (e.g., symptoms of flat or restricted affect).

In particular, the ability to identify and interpret facial expressions is imperative for effective non-vocal social communication. Individuals with schizophrenia have an impaired ability to both recognize faces and both discriminate and respond to emotional facial expressions, which are activities critical to social functioning (Addington \& Addington, 1998; Edwards et al., 2002; Kerr \& Neale, 1993; Mandal et al., 1998; Wolwer et al., 1996). However, to simplify, the findings of neuropsychological tests for emotional face recognition will be the focus of this section.

It has been repeatedly reported that patients with schizophrenia have deficits in the recognition of emotional faces. For example, Kohler et al. (2000) performed PEAT and the age recognition task with facial images for 35 patients with schizophrenia and 45 normal controls. The patients with schizophrenia performed worse than the controls on both the PEAT and age recognition task without differential deficits. In patients with schizophrenia, a poor performance on PEAT correlated with the severity of negative and positive symptoms, with no significant correlation for age recognition. Hooker and Park (2002) tested 20 chronic, medicated schizophrenia patients and 27 normal control participants in a battery of face recognition and affect recognition tasks. They demonstrated that schizophrenia patients were less accurate than normal control participants on face recognition, facial affect recognition and vocal affect recognition tasks, but among schizophrenia patients, only affect recognition performance was related to social functioning.

It was also reported that schizophrenia patients with persecutory delusions were slower than normal controls for identifying angry faces (Green \& Phillips, 2004). Patients also misattribute disgust and fear to neutral faces at a higher error rate than healthy controls (Kohler et al., 2003). These behavioral deficits in the recognition of emotional faces are stable over at least a few months (4 weeks [Gaebel \& Wolwer, 1992]; 4 and 12 weeks [Wolwer et al., 1996]; 12 weeks [Addington \& Addington, 1998]) and appear to be unrelated to either the symptom severity or medication status (Edwards et al., 2002). Differences among schizophrenia subtypes have also been reported. Paranoid-subtype patients are more accurate than non-paranoid-subtype patients at identifying negative facial expressions (Davis \& Gibson, 2000; Kline et al., 1992; Lewis \& Garver, 1995; Phillips et al., 1999). Although the reaction time is slower, paranoid-subtype patients may be more accurate judges of facial affect than normal control subjects. For example, Davis and Gibson (2000) reported an enhanced perception in paranoid-subtype patients relative to normal controls for negative facial expressions. However, the precise nature of emotional face recognition deficits in patients with schizophrenia remains unclear. 


\section{Neuroanatomical abnormalities of the fusiform gyrus in schizophrenic patients}

MRI studies have provided useful findings regarding the subtle structural brain abnormalities in patients with schizophrenia (Shenton et al., 2001). It should be noted that only positive MRI findings on FG have been included in this section. Paillère-Martinot et al. (2001) investigated the gray and white matter volumes in early onset schizophrenic patients using voxel-based morphometry. They reported significant gray matter reductions in the medial frontal gyri, left insula, left parahippocampus and left FG in patients. Lee et al. (2002) manually measured the FG volume and reported bilateral FG reduction, which was specific to first-episode schizophrenia compared with first-episode manic psychosis. Moreover, Onitsuka et al. (2003) reported an association between FG reduction and delayed facial recognition memory deficits in male patients with chronic schizophrenia. Premkumar et al. (2008) demonstrated that a longer duration of illness was associated with a smaller volume of left FG grey matter. In addition, the authors suggested that the right middle frontal cortex is particularly vulnerable to the long-term effects of schizophrenia, whereas the dorsomedial prefrontal cortex, FG and cerebellum are affected by both a long duration of illness and aging. In the study by Bangalore et al. (2009), the duration of untreated illness was found to be inversely correlated with gray matter changes in the left FG. Recently, Goghari et al. (in press) reported the left FG to decrease by $11 \%$ in patients and $7 \%$ in their biological relatives compared with normal controls.

The FG abnormalities represent a social communication disturbance of the disease, expressed symptomatically as asociality and social anhedonia, and neuropsychologically due to poor facial memory, and this three-variable relationship was uninfluenced by medication. Negative symptoms emphasize a loss of interest, motivation, and pleasure in social interaction which may reflect a risk factor that is present long before the onset of the disease and may mediate the relationship between the FG volume and lower scores on neuropsychological tests of facial recognition memory (Onitsuka et al., 2003) as well as lower levels of extraversion (Onitsuka et al., 2005), all of which may constitute the wellknown disease-related disturbance of social communication.

\section{Neuroimaging findings for neutral/emotional face recognition deficits in schizophrenia}

Patients with schizophrenia obviously have deficits in the neural substrate of visual face processing. As noted before, a number of structural and functional studies have also reported abnormalities in the FG. A meta-analysis of voxel-based MRI studies showed decreased volume of the left FG in around a quarter of studies, whereas only $5 \%$ or fewer showed a reduction in the right FG (Honea et al., 2005). Functionally, a deficit of FG activation relative to control subjects is also evident in functional MRI studies of matching facial identity and emotion (Quintana et al., 2003). Moreover, structural MRI has also revealed decreased STG gray matter volumes (Wright et al., 2000); thus other brain areas related face recognition may be affected in patients with schizophrenia.

In humans, various brain regions have been associated with emotion processing, as described before. Volume reductions of several brain regions involved in emotional face recognition have been reported, including the amygdala, prefrontal and orbitofrontal regions (Shenton et al., 2001; Wright et al., 2000). The amygdala may be structurally and 
functionally abnormal in patients with schizophrenia. Brain morphometric studies have indicated that there is a $6 \%$ bilateral amygdala volume reduction on average in patients with schizophrenia compared to healthy subjects (Wright et al., 2000). The responses of the amygdala to facial emotion appear to be abnormal in schizophrenic patients. For example, several studies have reported blood flow hypoactivation of the amygdala elicited by fearful faces compared with the activities to neutral faces in patients with schizophrenia (Aleman \& Kahn, 2005). On the other hand, recent studies have shown hyperactivation of the medial temporal lobe, especially the amygdala, to neutral faces in schizophrenic patients (Holt et al., 2006; Surguladze et al., 2006). Differences in the methodology and required tasks may account for some of the disparate results.

Functional neuroimaging studies have suggested several brain regional deficits in patients with schizophrenia, including a lack of FG activation relative to healthy subjects in facial affect and individual identification matching tasks (Quintana et al., 2003). Phillips et al. (1999) found differences between paranoid and non-paranoid schizophrenia patients using a gender discrimination task to compare expressions of fear, anger, and disgust to a mildly happy/neutral baseline in an fMRI study. Both groups showed decreased activation and accuracy at emotion identification relative to controls, and decreased amygdala activity to fearful faces. Paranoid patients showed increased visual cortex activity to fearful faces than non-paranoid patients, and abnormal activity in the inferior frontal cortex, anterior cingulate cortex, and visual cortex to angry expressions. Non-paranoid patients showed no activation of the insula to disgust, and some abnormal activation of the amygdala to faces showing disgust. There was also a trend for paranoid patients to be more accurate than non-paranoid patients at classifying negative emotions. In contrast to the decreased activation of visual and emotional processing areas in schizophrenic patients, functional neuroimaging studies have found increased responses in the amygdala and hippocampus to happy, neutral, and fearful expressions using non-face visual stimuli as the baseline of brain activity (Holt et al., 2006; Kosaka et al., 2002).

In summary, the results of a large number of neuroimaging studies suggest that facial emotion recognition in schizophrenic patients is impaired, especially for negative emotions. This impairment may be related to structural and functional abnormalities of the amygdala in patients with schizophrenia.

\section{Face-sensitive visual evoked potentials in schizophrenic patients}

In this section, the evoked potentials or ERPs elicited by neutral or emotional face images of schizophrenia will be reviewed for each component.

\subsection{P1 (P100)}

The P1 is a positive potential at the occipital area elicited at around $100 \mathrm{~ms}$ after the stimulus onset and generated within the extrastriate cortex (Pourtois et al., 2005). This potential is associated with the global processing of visual perception. The "global processing" is the initial stage of face categorization (Liu et al., 2002). Herrmann et al. (2004) reported a normal occipital P1 amplitude to images of neutral faces and buildings, with larger P1 amplitudes to faces than to buildings. Similarly, some studies reported normal P1 during processing of faces or facial affect in schizophrenic patients (Doniger et al., 2002; Schechter et al., 2005). On the other hand, some studies revealed P1 deficits during the processing of 
faces (Haenschel et al., 2008; Yeap et al., 2006); thus, the differences in P1 during face processing in schizophrenic patients remain to be elucidated.

The mechanism of the P1 evoked during processing of emotion identification remains unclear, and the effects of facial emotional expressions on the P1 are still being debated even for healthy subjects. The difficulties of required tasks may account for the P1 during emotion recognition (Di Russo et al., 1999; Hillyard et al., 1998). Furthermore, the P1 is very sensitive to the properties of the stimulus such as contrast, spatial frequency, and luminance (Tobimatsu et al., 1993; Rebai et al., 1998). Pourtois et al. (2005) reported that the P1 was significantly enhanced by low-spatially-filtered fearful faces in healthy subjects. However, several investigators reported no significant effects of facial expressions on P1 amplitudes in either normal controls or schizophrenics (Campanella et al., 2006; Johnston et al., 2005; Turetsky et al., 2007). Obayashi et al. (2009) reported no significant effects of the facial expressions for normal controls or patients with schizophrenia, regardless of spatiallyfiltered face images, thus suggesting that recognition of facial emotional expressions is higher-level visual processing, and that lower-level visual perception as reflected by the P1 cannot account for this process. Further studies will be necessary to reveal the mechanism responsible for the P1 component for face processing.

\subsection{N170}

The N170 is a negative potential recorded over occipitotemporal areas at around $170 \mathrm{ms,}$ and is considered to function as an index of the structural encoding of faces (Bentin \& Deouell, 2000), and the extraction of configural information (Goffaux et al., 2003; Rossion et al., 1999). The N170 is also associated with the local processing of identifying individual faces (Liu et al., 2002).

As noted before, the N170 is larger for faces than for objects in healthy subjects. However, Onitsuka et al. (2006) reported that male chronic schizophrenia patients showed specific N170 reduction to faces compared to normal controls (see Figure 3). Additionally, in this study, patients with schizophrenia, but not normal controls, showed a significant association between right posterior FG reduction and N170 reduction to faces but not to other objects at right posterior temporal electrodes. It has been repeatedly reported that patients with schizophrenia showed reduced N170 amplitudes to neutral and emotional faces (Caharel et al., 2007; Campanella et al., 2006; Lee et al., 2010; Lynn \& Salisbury, 2008; Obayashi et al., 2009; Turetsky et al., 2007).

However, the effects of facial emotional expressions on N170 still remain controversial. For example, Batty and Taylor (2003) found that the N170 amplitude to fearful faces was larger than the N170 to neutral faces in healthy subjects. On the other hand, it was reported that N170 was unaffected by any emotional expressions in healthy subjects (Eimer, 2000; Eimer \& Holmes, 2002). The authors documented that the N170 reflects the process of identification and recognition of faces, but not facial emotional expressions. Lynn and Salisbury (2008) demonstrated that healthy subjects showed bilateral differences in N170 amplitude among facial expressions, while schizophrenic patients failed to show this modulation. However, Obayashi et al. (2009) reported no significant effects of facial expressions for normal controls or schizophrenics, regardless of spatially-filtered face images. They also suggested possible dysfunction of the magnocellular and parvocellular pathways, which may underlie the deficits associated with facial recognition in schizophrenic patients. Therefore, electrophysiological studies have indicated that the N170 
amplitude reduction of schizophrenia during face and facial affect processing may reflect deficient processing of facial structures and facial structure encoding.

P7
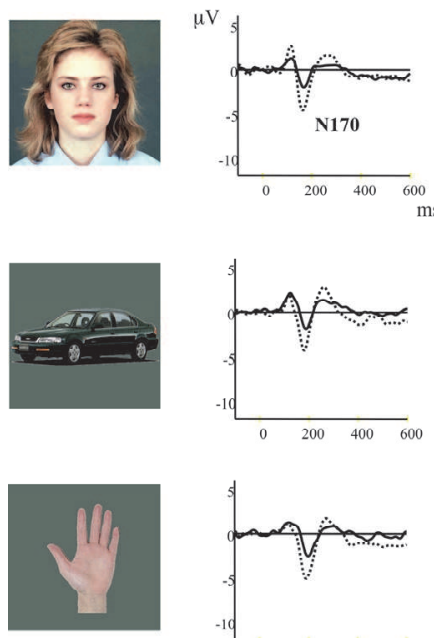

PO9
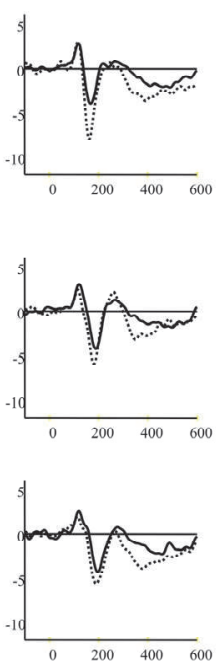

P8
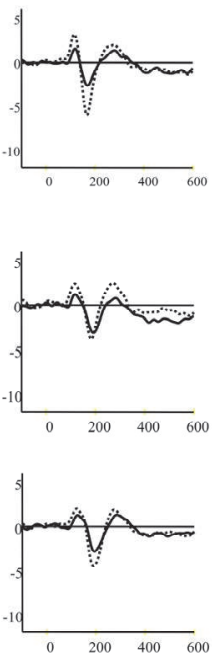

PO10
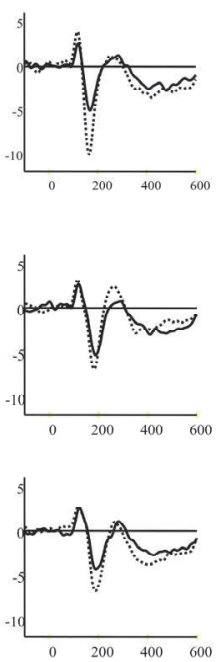

Fig. 3. The group average N170 waveforms at P7/P8 (typical N170 recording sites) and PO9/PO10 (more ventral sites with the largest effect).

The waveforms of patients with schizophrenia $(n=20)$ are shown in solid lines and those of normal controls $(n=16)$ are shown in dashed lines.

With regard to clinical correlations in patients with schizophrenia, a few studies have reported an association between the N170 and the clinical features. One study found significant associations between N170 and social dysfunction in patients with schizophrenia. Obayashi et al. (2009) reported correlations between reduced N170 amplitude in response to faces and lower Global Assessment of Functioning (GAF) scores in patients with schizophrenia. The N170 amplitude to faces could therefore function as a neurophysiological index of social functioning in schizophrenia. Further studies of social functioning of patients with schizophrenia using face processing paradigms would be of value to schizophrenia research. An fMRI study of healthy subjects suggested that the right FFA can be activated by highly trained object categories (Gauthier et al., 1999) (e.g., by birds in expert bird watchers). Moreover, Gauthier and Nelson (2001) speculate that the functional and anatomical specialization for faces in normal adults could simply be a result of our experience with human faces. As reviewed in this article, a number of findings suggest that anatomical/functional abnormalities underlie facial processing problems in patients with schizophrenia. Whether such abnormalities in schizophrenia are secondary to the limited experience of patients and/or are based on abnormalities in the neural substrate of face perception, it seems reasonable to speculate that abnormalities in face processing are related to the disinterest in social contact and social isolation observed in schizophrenic patients. In summary, a number of face-ERP studies have reported N170 amplitude reduction specific to faces, thus indicating that the neuronal populations involved in face perception may be 
specifically reduced in patients with schizophrenia. Moreover, schizophrenia may be characterized by deficits in the modulation of the N170 responses to different face stimuli.

\section{$10.3 \mathrm{~N} 250$}

Beyond the N170 potential, face-sensitive potentials also exist, but only a few studies have examined the N250 potential in patients with schizophrenia. The N250 is an affect-related negative potential that occurs approximately $250 \mathrm{~ms}$ after the stimulus onset at frontocentral electrode sites, and is sensitive to the emotional content of a face and familiar faces (Streit et al., 1999, 2001b; Tanaka et al., 2006).

In an MEG study, Streit et al. (2001a) found decreased amplitude in the 150-250 ms potential at left inferior parietal cortex, and in the $250-350 \mathrm{~ms}$ potential at the left inferior prefrontal cortex. In an ERP study, Streit et al. (2001b) reported decreased ERPs at frontal sites in schizophrenia patients compared to normal controls between 180-250 ms. These studies may indicate deficits in decoding of emotional information in patients with schizophrenia beyond the N170 potential.

However, the findings of previous studies tend to be mixed with regard to the N250 in patients with schizophrenia. For instance, other researchers have suggested that these deficits are secondary flow-on effects of broader deficits in the structural encoding of faces (Johnston et al., 2005; Turetsky et al., 2007), and reported abnormally small N170 amplitudes, but normal N250 responses. This finding suggested impaired facial feature encoding but unaffected emotion decoding (Johnston et al., 2005). Further research will therefore be needed to clarify this issue.

\section{Conclusion}

In this chapter, we have reviewed recent research on the neural mechanisms of facial recognition. Face perception may be one of the most familiar visual stimuli and the most important stimulus with regard to social interactions. Studies in monkeys showed faceselective neurons in the monkey brain. Human research to clarify the neuronal systems of face perception were also performed in patients, including those with prosopagnosia, and contributed significant information that helped in the elucidation of the human face processing system. Two models of human face processing, the Bruce and Young model and the Haxby model have so far been proposed. In addition, Bauer's model that has two neural visual pathways (the ventral stream and the dorsal stream) account for attentional face processing. The results from the study of human face processing show that there are face perception-related regions, including the FFA, STS, OFA, aMTG, the orbitofrontal cortex and the right ventrolateral prefrontal cortex, and the amygdala.

For face recognition deficits of patients with schizophrenia, this chapter reviewed findings of behavioral, structural and functional studies. Neuropsychological findings for face processing have indicated deficits in the formation and retention of memory for face configuration information in patients with schizophrenia. Brain morphometric studies have indicated that abnormalities of the FG may be associated with the pathophysiology of schizophrenia. Neurophysiologically, schizophrenia may be characterized by deficits in modulating the N170 in response to different face stimuli.

Although the respective roles of the different brain regions involved in face processing have emerged, both neuroimaging and neurophysiology studies, including FRP studies, have 
positively contributed to elucidating the neural network responsible for face processing in the human brain.

\section{References}

Addington, J. \& Addington, D. (1998). Facial affect recognition and information processing in schizophrenia and bipolar disorder. Schizophrenia Research, Vol.32, No.3, (August 1998), pp. 171-181, ISSN 0920-9964

Adolphs, R. (2003). Cognitive Neuroscience of human social behaviour. Nature reviews Neuroscience, Vol.4, (2003), pp. 165-178, ISSN 1471-003X

Aguirre, GK.; Zarahn, E. \& D'Esposito, M. (1998). An area within human ventral cortex sensitive to "building" stimuli. evidence and implications. Neuron, Vol.21, No.2, (August 1998), pp. 373-383, ISSN 0896-6273

Aleman, A. \& Kahn, RS. (2005). Strange feelings. do amygdala abnormalities dysregulate the emotional brain in schizophrenia? Progress in Neurobiology, Vol.77, No.5, (December 2005), pp. 283-298, ISSN 0301-0082

Allison, T.; Ginter, H.; McCarthy, G.; Nobre, AC.; Puce, A.; Luby, M. \& Spencer, DD. (1994). Face recognition in human extrastriate cortex. Journal of Neurophysiology, Vol.71, No.2, (February 1994), pp. 821-825, ISSN 0022-3077

Allison, T.; Puce, A.; Spencer, DD. \& McCarthy, G. (1999). Electrophysiological studies of human face perception. I: Potentials generated in occipitotemporal cortex by face and non-face stimuli. Cerebral Cortex, Vol.9, No.5, (August 1999), pp. 415-430, ISSN 1047-3211

Bangalore, SS.; Goradia, DD.; Nutche, J.; Diwadkar, VA.; Prasad, KM. \& Keshavan, MS. (2009). Untreated illness duration correlates with gray matter loss in first-episode psychoses. Neuroreport, Vol.20, No.7, (May 2009), pp. 729-734, ISSN 0959-4965

Batty, M. \& Taylor, MJ. (2003). Early processing of the six basic facial emotional expressions. Cognitive Brain Research,Vol.17, No.3, (October 2003), pp. 613-620, ISSN 0926-6410

Bauer, RM. (1984). Autonomic recognition of names and faces in prosopagnosia. a neuropsychological application of the Guilty Knowledge Test. Neuropsychologia, Vol.22, No.4, (1984), pp. 457-469, ISSN 0028-3932

Bentin, S.; Allison, T.; Puce, A.; Perez, E. \& McCarthy, G. (1996). Electrophysiological studies of face perception in humans. Journal of Cognitive Neuroscience, Vol.8, (1996), pp551565., ISSN 0898-929X

Bentin, S. \& Deouell, LY. (2000). Structural encoding and identification in face processing. ERP evidence for separate mechanisms. Cognitive Neuropsychology, Vol.17, No.1, (February 2000), pp. 35-54, ISSN 0264-3294

Blair, RJ.; Morris, JS.; Frith, CD.; Perrett, DI. \& Dolan, RJ. (1999). Dissociable neural responses to facial expressions of sadness and anger. Brain, Vol.122, No.Pt5, (May 1999), pp. 883-893, ISSN 0006-8950

Bodamer, J. (1947). Die Prosop-Agnosie. Archiv fur Psychiatrie und Nervenkrankheiten, Vol.179, (1947), pp. 6-54, ISSN 0003-9373

Bonda, E.; Petrides, M.; Ostry, D. \& Evans, A. (1996). Specific involvement of human parietal systems and the amygdala in the perception of biological motion. The Journal of Neuroscience.Vol.16, (1996), pp. 3737-3744, ISSN 0898-929X 
Botzel, K. \& Grusser, OJ. (1989). Electric brain potentials evoked by pictures of faces and non-faces. a search for "face-specific" EEG-potentials. Experimental Brain Research. Vol.77, (1989) pp. 349-360, ISSN 0014-4819

Botzel, K.; Schulze, S. \& Stodieck, SR. (1995). Scalp topography and analysis of intracranial sources of face-evoked potentials. Experimental Brain Research, Vol.104, No.1, (1995), pp. 135-143, ISSN 0014-4819

Bruce, V. \& Young, A. (1986). Understanding face recognition. British Psychological Society, Vol.77, No ( Pt 3), (1986), pp. 305-327, ISSN 1359-107X

Caharel, S.; Bernard, C.; Thibaut, F.; Haouzir, S.; Di Maggio-Clozel, C,; Allio, G.; Fouldrin, G.; Petit, M., Lalonde, R. \& Rebaï, M. (2007). The effects of familiarity and emotional expression on face processing examined by ERPs in patients with schizophrenia. Schizophrenia Research, Vol.95, No.1-3, (September 2007), pp. 186-196, ISSN 0920-9964

Calder, AJ.; Lawrence, AD.; Keane, J.; Scott, SK.; Owen, AM.; Christoffels, I. \& Young, AW. (2002). Reading the mind from eye gaze. Neuropsychologia, Vol.40, No.,8 (August 2002), pp. 1129-1138, ISSN 0088-3932

Calvert, GA.; Bullmore, ET.; Brammer, MJ.; Campbell, R.; Williams, SC.; McGuire, PK.; Woodruff, PW.; Iversen, SD. \& David, AS. (1997). Activation of auditory cortex during silent lipreading. Science, Vol.276, No.5312, (April 1997), pp. 593-596, ISSN 0193-4511

Campanella, S.; Montedoro, C.; Streel, E.; Berbanck, P. \& Rosier, V. (2006). Early visual components (P100.; N170) are disrupted in chronic schizophrenic patients. an event-related potentials study. Neurophysiologie Clinique, Vol.36, No.2, (March 2006), pp. 71-78, ISSN 0987-7053

Chao, LL.; Haxby, JV. \& Martin, A. (1999a). Attribute-based neural substrates in temporal cortex for perceiving and knowing about objects. Nature Neuroscience, Vol.10, No.2, (October 1999), pp. 913-919, ISSN 1097-6256

Chao, LL.; Martin, A. \& Haxby, JV. (1999b). Are face-responsive regions selective only for faces? Neuroreport, Vol.29, No.10, (September 1999), pp. 2945-2950, ISSN 0959-4965

Clark, VP.; Keil, K.; Maisog, JM.; Courtney, S.; Ungerleider, LG. \& Haxby, JV. (1996). Functional magnetic resonance imaging of human visual cortex during face matching. a comparison with positron emission tomography. Neuroimage, Vol.4, No.1, (August 1996), pp. 1-15, ISSN 1053-8119

Damasio, A.; Damasio, H. \& Van Hoesen, GW. (1982). Prosopagnosia. anatomic basis and behavioral mechanisms. Neurology, Vol.32, No.4, (April 1982), pp. 331-341, ISSN 0028-3878

Damasio, AR.; Tranel, D. \& Rizzo, M. (2000). Disorders of complex visual processing., In: Principles of Behavioral and Cognitive Neurology, Mesulam, MM., pp. 335-339, Oxford University Press Inc., ISBN-13: 978-0195134759, New York.

Davis, PJ. \& Gibson, MG. (2000). Recognition of posed and genuine facial expressions of emotion in paranoid and nonparanoid schizophrenia. Journal of Abnormal Psychology, Vol.109, No.3, (August 2000), pp. 445-450, ISSN 0021-843X

Decety, J. \& Grezes, J. (1999). Neural mechanisms subserving the perception of human actions. Trends in Cognitive Sciences, Vol., No.5, (May 1999), pp. 172-178, ISSN 13646613 
Di Russo, F. \& Spinelli, D.(1999) Electrophysiological evidence for an early attentional mechanism in visual processing in humans. (1999). Vision Research, Vol.39, No.18, (September 1996), pp. 2975-2985, ISSN 0042-6989

Doniger, GM.; Foxe, JJ.; Murray, MM.; Higgins, BA. \& Javitt, DC. (2002). Impaired visual object recognition and dorsal/ventral stream interaction in schizophrenia. Archives of General Psychiatry, Vol.59, No.11, (Novemer 2002), pp. 1011-1020, ISSN 0003-990X

Edwards, J.; Jackson, HJ. \& Pattison, PE. (2002). Emotion recognition via facial expression and affective prosody in schizophrenia. a methodological review. Clinical Psychology Review, Vol.22, No.6, (July 2002), pp. 789-832, ISSN 0272-7358

Eifuku, S.; De Souza, WC.; Tamura, R.; Nishijo, H. \& Ono, T. (2004). Neuronal correlates of face identification in the monkey anterior temporal cortical areas, Journal of Neurophysiology, Vol.91, No.1, (January 2004), pp. 358-371, ISSN 0022-3077

Eimer, M. \& Holmes, A. (2002). An ERP study on the time course of emotional face processing. Neuroreport, Vol.13, No.2, (January 2003), pp. 427-431, ISSN 1530-7026

Eimer, M. (2000). The face-specific N170 component reflects late stages in the structural encoding of faces. Neuroreport, Vol.11, (2000), pp. 2319-2324, ISSN 0959-4965

Ekman, P. \& Friesen, WV. (1978). Facial Action Coding System. Palo Alto.; CA. Consulting Psychologists Press. Inc.

Ekman, P. (1972). Universals and cultural differences in facial expressions of emotion. Journal of Personality and Social Psychology, Vol.53, No.4, (October 1972), pp.712-717, ISSN 0022-3514

Ekman, P. (1994). Strong evidence for universals in facial expressions. a reply to Russell's mistaken critique. Psychological Bulletin, Vol.115, No.2, (March 1994), pp. 268-287, ISSN 0734-3124

Ellis, HD. \& Young, AW. (1990). Accounting for delusional misidentifications. British Psychological Society, Vol.157, (1990), pp. 239-248, ISSN 1359-107X

Epstein, R. \& Kanwisher, N. (1998). A cortical representation of the local visual environment. Nature, Vol.6676, No.392, (April 1998), pp. 598-601, ISSN 0028-0836

Farah, MJ. (1991). Patterns of co-occurrence among the associative agnosias. implications for visual object representation. Cognitive Neuropsychology, Vol.8, (1991), pp. 1-19, ISSN 0264-3294

Farroni, T.; Csibra, G.; Simion, F. \& Johnonson, MH. (2002). Eye contact detection in humans from birth, Proceedings of the National Academy of Sciences of the United States of America, Vol.99, No.14, (July 2002), pp. 9602-9605, ISSN 0027-8424

Gaebel, W. \& Wolwer, W. (1992). Facial expression and emotional face recognition in schizophrenia and depression. European Archives of Psychiatry and Clinical Neuroscience, Vol.242, No.1, (1992), pp. 46-52, ISSN 0940-1334

Gauthier, I. \& Nelson, CA. (2001). The development of face expertise. Current Opinion in Neurobiology, Vol.11, No.2, (April 2001), pp. 291-224, ISSN 0959-4388

Gauthier, I. \& Tarr, MJ. (1997). Becoming a "Greeble" expert. exploring mechanisms for face recognition. Vision Research, Vol.37, No.12, (Junuary 1997), pp. 1673-1682, ISSN. 0042-6989

Gauthier, I.; Tarr, MJ.; Anderson, AW.; Skudlarski, P. \& Gore, JC. (1999). Activation of middle fusiform 'face area' increases with expertise in recognizing novel objects. Nature Neuroscience, Vol.6, No.2, (Junuary 1999), pp. 568-573, ISSN 1097-6256 
Goffaux, V.; Gauthier, I. \& Rossion, B. (2003). Spatial scale contribution to early visual differences between face and object processing. Brain Research. Cognitive Brain Research, Vol.16, No.3, (May 2003), pp. 416-424, ISSN 0926-6410

Goghari, VM.; Macdonald, AW 3rd. \& Sponheim, SR. (in press). Temporal lobe structures and facial emotion recognition in schizophrenia patients and nonpsychotic relatives. Schizophrenia bulletin, (in press), ISSN 1787-9965

Gorno-Tempini, ML.; Pradelli, S.; Serafini, M.; Pagnoni, G.; Baraldi, P.; Porro, C.; Nicoletti, R.; Umità, C. \& Nichelli, P. (2001). Explicit and incidental facial expression processing. an fMRI study. Neuroimage, Vol.14, No.2, (August 2001), pp. 465-473, ISSN 1053-8119

Green, MJ. \& Phillips, ML. (2004). Social threat perception and the evolution of paranoia. Neuroscience and Biobehavioral Reviews, Vol.28, No3., (May 2004), pp. 333-342, ISSN. 0149-7634

Grill-Spector, K.; Knouf, N. \& Kanwisher, N. (2004). The fusiform face area subserves face perception.; not generic within-category identification. Nature Neuroscience, Vol.7, No.5, (May 2004), pp. 555-562, ISSN 1097-6256

Grossman, E.; Donnelly, M.; Price, R.; Pickens, D.; Morgan, V.; Neighbor, G. \& Blake, R. (2000). Brain areas involved in perception of biological motion. Journal of Cognitive Neuroscience, Vol.12, (2000), pp. 711-720, ISSN 0898-929X

Gur, RC.; Sara, R.; Hagendoorn, M.; Marom, O.; Hughett, P.; Macy, L.; Turner, T.; Bajcsy, R.; Posner, A. \& Gur, RE. (2002). A method for obtaining 3-dimensional facial expressions and its standardization for use in neurocognitive studies. Journal of Neuroscience Methods, Vol.115, No.2, (April 2002), pp. 137-143, ISSN 0165-0270

Haenschel, C.; Bittner, RA.; Haertling, F.; Rotarska-Jagiela, A.; Maurer, K.; Singer, W. \& Linden, DE. (2008). Contribution of impaired early-stage visual processing to working memory dysfunction in adolescents with schizophrenia. a study with event-related potentials and functional magnetic resonance imaging. Archives of General Psychiatry, Vol.64, No.11, (November 2007), pp. 1229-1240, ISSN 0003-990X

Halgren, E.; Dale, AM.; Sereno, MI.; Tootell, RB.; Marinkovic, K. \& Rosen, BR. (1999). Location of human face-selective cortex with respect to retinotopic areas. Human Brain Mapping, Vol.7, No.1, (1999), pp. 29-37, ISSN. 1065-9471

Hasselmo, ME.; Rolls, ET. \& Baylis, GC. (1989). The role of expression and identity in the face-selective responses of neurons in the temporal visual cortex of the monkey, Behavioural Brain Research, Vol.32, No.3, (April 1989), pp. 203-218, ISSN 0166-4328

Haxby, JV.; Hoffman, EA. \& Gobbini, MI. (2002). Human neural systems for face recognition and social communication. Biological Psychiatry, Vol.51, No.1, (January 2002), pp. 5967, ISSN 0006-3223

Haxby, JV.; Hoffman, EA. \& Gobbini, MI. (2000). The distributed human neural system for face perception. Trends in Cognitive Sciences, Vol.4, (2000), pp. 223-233, ISSN 13646613

Haxby, JV.; Ungerleider, LG.; Clark VP.; Schouten, JL.; Hoffman, EA. \& Martin, A. (1999). The effect of face inversion on activity in human neural systems for face and object perception. Neuron, Vol.22, No.1, (January 1999), pp. 189-199, ISSN 0896-6273

Henson, RN.; G-GY.; Ganel, T.; Otten, LJ.; Quayle, A. \& Rugg, MD. (2003). Electrophysiological and haemodynamic correlates of face perception.; recognition and priming. Cereb Cortex, Vol.13, No.7, (July 2003), pp 793-805, ISSN 1047-3211 
Herrmann, MJ.; Ellgring, H. \& Fallgatter, AJ. (2004). Early-stage face processing dysfunction in patients with schizophrenia. The American Journal of Psychiatry, Vol.161, No.5, (May 2004), pp. 915-917, ISSN 0002-953X

Hillyard, SA.; Teder-Salejarvi, WA. \& Munte, TF. (1998). Temporal dynamics of early perceptual processing. Current Opinion in Neurobiology, Vol.8, No.2, (April 1998), pp. 202-210, ISSN 0959-4388

Hoffman, EA. \& Haxby, JV. (2000). Distinct representations of eye gaze and identity in the distributed human neural system for face perception. Nature Neuroscience,Vol.3, No.1, (January 2000), pp. 80-84, ISSN 1097-6256

Holt, DJ.; Kunkel, L.; Weiss, AP.; Goff, DC.; Wright, CI.; Shin, LM.; Rauch, SL.; Hootnick, J. \& Heckers, S. (2006). Increased medial temporal lobe activation during the passive viewing of emotional and neutral facial expressions in schizophrenia. Schizophrenia Research, Vol.82, No.2-3, (February 2006), pp. 153-162, ISSN 0920-9964

Honea, R.; Crow, TJ.; Passingham, D. \& Mackay, CE. (2005). Regional deficits in brain volume in schizophrenia. a meta-analysis of voxel-based morphometry studies. The American Journal of Psychiatry, Vol.162, No.12, (Dember 2005), pp. 2233-2245, ISSN 0002-953X

Hooker, C. \& Park, S. (2002). Emotion processing and its relationship to social functioning in schizophrenia patients. Psychiatry Research,Vol.112, No.1, (September 2002), pp. 4150, ISSN 0165-1781

Hooker, CI.; Paller, KA.; Gitelman, DR.; Parrish, TB.; Mesulam, MM. \& Reber, PJ. (2003). Brain networks for analyzing eye gaze. Cognitive Brain Research, Vol.,17 No.2, (July 2003), pp. 406-418, ISSN0926-6410

Ishai, A.; Ungerleider, LG.; Martin, A.; Schouten, JL. \& Haxby, JV. (1999). Distributed representation of objects in the human ventral visual pathway. Proceedings of the National Academy of Sciences of the United States of America, Vol.96, No.16, (August 1999), pp. 9379-9384, ISSN 0027-8424

Itier, RJ. \& Taylor, MJ. (2004). Source analysis of the N170 to faces and objects. Neuroreport, Vol.15, No.8, (Junary 2004), pp. 1261-1265, ISSN 0959-4965

Izard, CE. (1994). Innate and universal facial expressions. evidence from developmental and crosscultural research. Psychological Bulletin,Vol. 115, No.2, (March 1994), pp288299, ISSN 0734-3124

Jeffreys, DA. (1989). A face-responsive potential recorded from the human scalp. Experimental Brain Research, Vol.78, No.1, (1989), pp. 193-202, ISSN 0014-4819

Johnston, PJ.; Stojanov, W.; Devir, H. \& Schall, U. (2005). Functional MRI of facial emotion recognition deficits in schizophrenia and their electrophysiological correlates. Eurpean Journal of Neuroscience, Vol.22, No.5, (September 2005), pp. 1221-1232, ISSN 0953-816X

Kanwisher, N.; McDermott, J. \& Chun, MM. (1997). The fusiform face area. a module in human extrastriate cortex specialized for face perception. The Journal of Neuroscience, Vol.17, No.11, (Junuary 1997), pp. 4302-4311, ISSN 0976-3155

Kerr, SL. \& Neale, JM. (1993). Emotion perception in schizophrenia. specific deficit or further evidence of generalized poor performance? Journal of Abnormal Psychology, Vol.102, No.2, (May 1993), pp. 312-318, ISSN 0021-843X 
Kline, JS.; Smith, JE. \& Ellis, HC. (1992). Paranoid and nonparanoid schizophrenic processing of facially displayed affect. Journal of Psychiatric Research, Vol.26, No.3, (July 1992), pp. 169-182, ISSN 0022-3956

Kohler, CG.; Turner, TH.; Bilker, WB.; Brensinger, CM.; Siegel, SJ.; Kanes, SJ.; Gur, RE. \& Gur, RC. (2003). Facial emotion recognition in schizophrenia. intensity effects and error pattern. The American Journal of Psychiatry,Vol.160, No.10, (October 2003), pp. 1768-1774,ISSN0002-953X.

Kohler, CG.; Bilker, W.; Hagendoorn, M.; Gur, RE. \& Gur, RC. (2000). Emotion recognition deficit in schizophrenia. association with symptomatology and cognition. Biological Psychiatry, Vol.48, No.2, (July 2000), pp127-136., ISSN 0006-3223

Kosaka, H.; Omori, M.; Murata, T.; Iidaka, T.; Yamada, H.; Okada, T.; Takahashi, T.; Sadato, N.; Itoh, H.; Yonekura, Y. \& Wada, Y. (2002). Differential amygdala response during facial recognition in patients with schizophrenia. an fMRI study. Schizophrenia Research, Vol.57, No.1, (September 2002), pp. 87-95, ISSN 0920-9964

LaBar, KS.; Gatenby, JC.; Gore, JC.; LeDoux, JE. \& Phelps, EA. (1998). Human amygdala activation during conditioned fear acquisition and extinction. a mixed-trial fMRI study. Neuron, Vol.20, No.5, (May 1998), pp. 937-945, ISSN 0896-6273.

Landis, T.; Regard, M.; Bliestle, A. \& Kleihues, P. (1988). Prosopagnosia and agnosia from noncanonical views. An autopsied case. Brain, Vol.111, No.Pt6, (December 1988), pp. 1287-1297, ISSN 0006-8950

Lee, C-U.; Shenton, ME.; Salisbury, DF.; Kasai, K.; Onitsuka, T.; Dickey, CC.; YurgelunTodd, D.; Kikinis, R.; Jolesz, FA. \& McCarley, RW. (2002). Fusiform gyrus volume reduction in first-episode schizophrenia. a magnetic resonance study. Archives of General Psychiatry, Vol.59, No.9, (September 2002), pp. 775-781, ISSN 0003-990X

Lee, SH.; Kim, EY.; Kim, S. \& Bae, SM. (2010). Event-related potential patterns and gender effects underlying facial affect processing in schizophrenia patients. Neuroscience Research, Vol.67, No.2, (June 2010), pp. 172-180, ISSN 0168-0102

Leppanen, JM. \& Hietanen, JK. (2004). Positive facial expressions are recognized faster than negative facial expressions.; but why? Psychological Research, Vol.69, No.1-2, (December 2004), pp. 22-29, ISSN 0340-0727

Lewis, SF. \& Garver, DL. (1995). Treatment and diagnostic subtype in facial affect recognition in schizophrenia. Journal of Psychiatric Research, Vol.29, No.1, (February 1995), pp. 5-11, ISSN 0022-3956

Liu, J.; Harris, A. \& Kanwisher, N. (2002). Stages of processing in face perception. an MEG study. Nature Neuroscience, Vol.5, No.9, (September 2002), pp. 910-6, ISSN 1097-6256

Lu, S.; Hamalainen, MS.; Hari, R.; Ilmoniemi, RJ.; Lounasmaa, OV.; Sams, M. \& Vilkman, V. (1991). Seeing faces activates three separate areas outside the occipital visual cortex in man. Neuroscience, Vol.43, No.2-3, (1991), pp. 287-290, ISSN 0306-4522

Lynn, SK. \& Salisbury, DF. (2008). Attenuated modulation of the N170 ERP by facial expressions in schizophrenia. Clinical Electroencephalography and Neuroscience, Vol.39, No.2, (April 2008), pp108-111., ISSN 1550-0594

Mandal, MK.; Pandey, R. \& Prasad, AB. (1998). Facial expressions of emotions and schizophrenia. a review. Schizophrenia Bulletin, Vol.24, No.3, (1998), pp. 399-412., ISSN 1787-9965

Marinkovic, K.; Trebon, P.; Chauvel, P. \& Halgren, E. (2000). Localised face processing by the human prefrontal cortex. face-selective intracerebral potentials and post-lesion 
deficits. Cognitive Neuropsychology. Vol.17, No.1, (February 2000), pp. 187-199, ISSN 0264-3294

Martin, A. \& Chao, LL. (2001). Semantic memory and the brain. structure and processes. Current Opinion in Neurobiology, Vol.11, (2001), pp. 194-201, ISSN 0959-4388

Morris, JS.; DeGelder, B.; Weiskrantz, L. \& Dolan, RJ. (2001). Differential extrageniculostriate and amygdala responses to presentation of emotional faces in cortically blind field. Brain, Vol.124, No.Pt6, (Junuary 2001), pp. 1241-1252, ISSN 0006-8950

Morris, JS.; Friston, KJ.; Buchel, C.; Frith, CD.; Young AW.; Calder, AJ. \& Dolan, RJ. (1998). A neuromodulatory role for the human amygdala in processing emotional facial expressions. Brain, Vol121., No.Pt1, (January 1998), pp. 47-57, ISSN 0006-8950

Morton, J. \& Johnson, MH. (1991). CONSPEC and CONLERN: a two-process theory of infant face recognition, Psychological Review, Vol.98, No.2, (April 1991), pp. 164-181, ISSN 0033-295X

Naidich, TP.; Daniels, DL.; Haughton, VM.; Williams, A.; Pojunas, K. \& Palacios, E. (1987). Hippocampal formation and related structures of the limbic lobe. anatomic-MR correlation. Radiology, Vol.162, No.3, (March 1987), pp. 747-754, ISSN 0033-8419

Nakamura, K.; Kawashima, R.; Sato, N.; Nakamura, A.; Sugiura, M.; Kato, T.; Hatano, K.; Ito, K.; Fukuda, H.; Schormann, T. \& Zilles, K. (2000). Functional delineation of the human occipito-temporal areas related to face and scene processing. A PET study. Brain, Vol.123, No.Pt9, (Septenber 2000), pp. 1903-1912, ISSN 0006-8950

Nakamura, K.; Mikami, A. \& Kubota, K. (1992). Activity of single neurons in the monkey amygdala during performance of a visual discrimination task, Journal of Neurophysiology, Vol.67, No.6, (June 1992), pp. 1447-1463, ISSN 0022-3077

Narumoto, J.; Okada, T.; Sadato, N.; Fukui, K. \& Yonekura, Y. (2001). Attention to emotion modulates fMRI activity in human right superior temporal sulcus. Cognitive Brain Research, Vol.12, No.2, (October 2001), pp. 225-231, ISSN 0926-6410

Obayashi, C.; Nakashima, T.; Onitsuka, T.; Maekawa, T.; Hirano, Y.; Hirano, S.; Oribe, N.; Kaneko, K.; Kanba, S. \& Tobimatsu, S. (2009). Decreased spatial frequency sensitivities for processing faces in male patients with chronic schizophrenia. Clinical Neurophysiology, Vol.120, No.8, (August 2009), pp. 1525-1533, ISSN 13882457

Onitsuka, T.; Nestor, PG.; Gurrera, RJ.; Shenton, ME.; Kasai, K.; Frumin, M.; Niznikiewicz, MA. \& McCarley, RW. (2005). Association between reduced extraversion and right posterior fusiform gyrus gray matter reduction in chronic schizophrenia. The American Journal of Psychiatry, Vol.162, No.3, (March 2005), pp. 599-601, ISSN 0002953X

Onitsuka, T.; Niznikiewicz, MA.; Spencer, KM.; Frumin, M.; Kuroki, N.; Lucia, LC.; Shenton, ME. \& McCarley, RW. (2006). Functional and structural deficits in brain regions subserving face perception in schizophrenia. The American Journal of Psychiatry, Vol.163, No.3, (March 2006), pp. 455-462, ISSN 0002-953X

Onitsuka, T.; Shenton, ME.; Kasai, K.; Nestor, PG.; Toner, SK.; Kikinis, R.; Jolesz, FA. \& McCarley, RW. (2003). Fusiform gyrus volume reduction and facial recognition in chronic schizophrenia. Archives of General Psychiatry, Vol.60, No.8, (August 2003), pp. 349-355, ISSN 0003-990X

Ono, M.; Kubik, S. \& Abernathey, CD. (1990). Atlas of the cerebral sulci. Georg Thieme Verlag, ISBN-13: 978-0865773622, New York 
Oram, MW. \& Perrett, DI. (1996). Integration of form and motion in the anterior superior temporal polysensory area (STPa) of the macaque monkey, Journal of Neurophysiology, Vol.76, No.1, (July 1996), pp. 109-129, ISSN 0022-3077

Paille-Martinot, ML.; Caclin, A.; Artiges, E.; Poline, JB.; Joliot, M.; Mallet, L.; Recasens, C.; Attar-Lévy, D. \& Martinot, JL. (2001). Cerebral gray and white matter reductions and clinical correlations in patients with early onset schizophrenia. Schizophrenia Research, Vol.50, No.1-2, (May 2001), pp. 19-26, ISSN 0920-9964

Perrett, DI.; Smith, PA.; Mistlin, AJ.; Chitty, AJ.; Head, AS.; Potter, DD.; Broennimann, R.; Milner, AD. \& Jeeves, MA. (1985). Visual analysis of body movements by neurones in the temporal cortex of the macaque monkey. a preliminary report. Behavioural Brain Research, Vol.16, No.2-3, (August 1985), pp. 153-170, ISSN 0166-4328

Perrett, DI.; Smith, PA.; Potter, DD.; Mistlin, AJ.; Head, AS.; Milner, AD. \& Jeeves, MA. (1984). Neurones responsive to faces in the temporal cortex. studies of functional organization, sensitivity to identity and relation to perception, Human Neurobiology, Vol.4, No.3, (1984), pp. 197-208, ISSN 0721-9075

Phillips, ML.; Williams, L.; Senior, C.; Bullmore, ET.; Brammer, MJ.; Andrew, C.; Williams, SCR. \& David, AS. (1999). A differential neural response to threatening and nonthreatening negative facial expressions in paranoid and non-paranoid schizophrenics. Psychiatry Research, Vol.92, No.1, (November 1999), pp. 11-31, ISSN 0165-1781

Pourtois, G.; Dan, ES.; Grandjean, D.; Sander, D. \& Vuilleumier, P. (2005). Enhanced extrastriae visual response to bandpass spatial frequency filtered fearful faces. time course and topographic evoked-potentials mapping. Human Brain Mapping,Vol26., No.1, (September 2005), pp. 65-79, ISSN 1065-9471

Premkumar, P.; Fannon, D.; Kuipers, E.; Cooke, MA.; Simmons, A. \& Kumari, V. (2008). Association between a longer duration of illness, age and lower frontal lobe grey matter volume in schizophrenia. Behavioural Brain Research, Vol.193, No.1, (November 2008), pp. 132-139, ISSN 0166-4328

Puce, A.; Allison, T.; Bentin, S.; Gore, JC. \& McCarthy, G. (1998). Temporal cortex activation in humans viewing eye and mouth movements. The Journal of Neuroscience, Vol.18, No.6, (March 1998), pp. 2188-2199, ISSN 0976-3155

Puce, A.; Epling, JA.; Thompson, JC. \& Carrick, OK. (2007). Neural responses elicited to face motion and vocalization pairings. Neuropsychologia, Vol.45, No.1, (January 2007), pp. 93-106, ISSN 0028-3932

Quintana, J.; Wong, T.; Ortiz-Portillo, E.; Marder, SR. \& Mazziotta, JC. (2003) Right lateral fusiform gyrus dysfunction during facial information processing in schizophrenia. Biological Psychiatry, Vol.53, No.12, (Junuary 2003), pp. 1099-1112, ISSN 0006-3223

Rebai, M.; Bernard, C.; Lannou, J. \& Jouen, F. (1998). Spatial frequency and right hemisphere. an electrophysiological investigation. Brain and Cognition, Vol.36, No.1, (February 1998), pp. 21-29, ISSN 0278-2626

Rolls, ET.; Critchley, HD.; Browning, AS. \& Inoue, K. (2006). Face-selective and auditory neurons in the primate orbitofrontal cortex. Experimental Brain Research, Vol.170, No.1, (March 2006), pp. 74-87, ISSN 0014-4819

Rossion, B.; Delvenne, JF.; Debatisse, D.; Goffaux, V.; Bruyer, R.; Crommelinck, M. \& Guérit, JM. (1999). Spatio-temporal localization of the face inversion effect. an event-related 
potentials study. Biological Phychology, Vol.50, No.3, (July 1999), pp. 173-189, ISSN 0301-0511

Rossion, B.; Gauthier, I.; Goffaux, V.; Tarr, MJ. \& Crommelinck, M. (2002). Expertise training with novel objects leads to left lateralized face-like electrophysiological responses. Psychological Science,Vol.13, No.3, (May 2002), pp. 250-257, ISSN 0956-7976

Rossion, B.; Gauthier, I.; Tarr, MJ.; Despland, P.; Bruyer, R.; Linotte, S. \& Crommelinck, M. (2000). The N170 occipito-temporal component is delayed and enhanced to inverted faces but not to inverted objects. an electrophysiological account of facespecific processes in the human brain. Neuroreport, Vol.11, No.1, (January 2000), pp. 69-74, ISSN 0959-4965

Schechter, I.; Butler, PD.; Zemon, V.; Revheim, N.; Saperstein, AM.; Jalbrzikowski, M.; Pasternak, R.; Silipo, G. \& Javitt, DC. (2005). Impairments of earlystage transient visual evoked potentials to magno- and parvocellular-selective stimuli in schizophrenia. Clinical Neurophysiology, Vol.116, No.9, (September 2005), pp.22042215, ISSN 1388-2457

Sergent, J.; Ohta, S. \& MacDonald, B. (1992). Functional neuroanatomy of face and object processing. A positron emission tomography study. Brain, (February 1992), Pt 1. 1536, ISSN 0006-8950

Sheline, YI.; Barch, DM.; Donnelly, JM.; Ollinger, JM.; Snyder, AZ. \& Mintun, MA. (2001). Increased amygdala response to masked emotional faces in depressed subjects resolves with antidepressant treatment. an fMRI study. Biological Psychiatry, Vol.50, No.1, (November 2001), pp. 651-658,ISSN. 0006-3223

Shenton, ME.; Dickey, CC.; Frumin, M. \& McCarley, RW. (2001). A review of MRI findings in schizophrenia. Schizophrenia Research, Vol.49, No.1-2, (April 2001), pp. 1-52, ISSN 0920-9964

Silver, H.; Shlomo, N.; Turner, T. \& Gur, RC. (2002). Perception of happy and sad facial expressions in chronic schizophrenia. evidence for two evaluative systems. Schizophrenia Research, Vol.55, No.1-2, (May 2002), pp. 171-177, ISSN 0920-9964

Smith, NK.; Cacioppo, JT.; Larsen, JT. \& Chartrand, TL. (2003). May I have your attention, please: electrocortical responses to positive and negative stimuli. Neuropsychologia, Vol.41, No.2, (2003), pp. 171-183, ISSN 0028-3932.

Spiridon, M. \& Kanwisher, N. (2002). How distributed is visual category information in human occipito-temporal cortex? An fMRI study. Neuron, Vol.35, No.6, (September 2002), pp. 1157-1165, ISSN 0896-6273

Streit, M.; Ioannides, AA.; Sinneman, T.; Wolwer, W.; Dammers, J.; Zilles, K. \& Gaebel, W. (2001a). Disturbed facial affect recognition in patients with schizophrenia associated with hypoactivity in distributed brain regions: a magnetoencephalographic study. The American Journal of Psychiatry, Vol.158, No.9, (September 2001), pp. 1429-1436, ISSN 0002-953X

Streit, M.; Ioannides, AA.; Liu, L.; Wolwer, W.; Dammers, J.; Gross, J.; Gaebel, W. \& MüllerGärtner, HW. (1999). Neurophysiological correlates of the recognition of facial expressions of emotion as revealed by magnetoencephalography. Cognitive Brain Research, Vol.7, No.1, (February 1999), pp. 481-491, ISSN 0926-6410

Streit, M.; Wolwer, W.; Brinkmeyer, J. Ihl, R. \& Gaebel, W. (2001b). EEG correlates of facial affect recognition and categorisation of blurred faces in schizophrenic patients and 
healthy volunteers. Schizophrenia Research, Vol.49, No.1-2, (April 2001), pp. 145-155, ISSN 0920-9964

Surguladze, S.; Russell, T.; Kucharska-Pietura, K.; Travis, MJ.; Giampietro, V.; David, AS. \& Phillips, ML. (2006). A reversal of the normal pattern of parahippocampal response to neutral and fearful faces is associated with reality distortion in schizophrenia. Biological Psychiatry, Vol.60, No.5, (September 2006), pp. 423-431, ISSN 0006-3223

Tanaka, JW.; Curran, T.; Porterfield, AL. \& Collins, D. (2006). Activation of preexisting and acquired face representations. the N250 event-related potential as an index of face familiarity. Journal of Cognitive Neuroscience, Vol.18, No.9, (September 2006), pp. 1488-1497, ISSN. 0898-929X

Tanaka, JW. \& Curran, T. (2001). A neural basis for expert object recognition. Psychological Science, Vol.12, (2001), pp. 43-47 ISSN 0956-7976

Thorpe, SJ.; Rolls, ET. \& Maddison, S. (1983). The orbitofrontal cortex. neuronal activity in the behaving monkey, Experimental Brain Research, Vol.49, No.1, (1983), pp. 93-115, ISSN 0014-4819

Tobimatsu, S.; Kurita-Tashima, S.; Nakayama-Hiromatsu, M.; Akazawa, K. \& Kato, M. (1993). Age-related changes in pattern visual evoked potentials. differential effects of luminance; contrast and check size. Electroencephalography and clinical Neurophysiology, Vol.88, No.1, (January 1993), pp. 12-19, ISSN 0013-4694

Tong, F.; Nakayama, K.; Moscovitch, M.; Weinrib, O. \& Kanwisher, N. (2000). Response properties of the human fusiform face area. Cognitive Neuropsychology,Vol.17, No.1, (February 2000), pp. 257-280, ISSN 0264-3294

Turetsky, BI.; Kohler, CG.; Indersmitten, T.; Bhati, MT.; Charbonnier, D. \& Gur, RC. (2007). Facial emotion recognition in schizophrenia: when and why does it go awry? Schizophrenia Research, Vol.94, No.1-3, (August 2007), pp. 253-263, ISSN 0920-9964

Vignal, JP.; Chauvel, P. \& Halgren, E. (2000). Localised face processing by the human prefrontal cortex. stimulation-evoked hallucinations of faces. Cognitive Neuropsychology, Vol.17, No.1, (February 2000), pp. 281-291, ISSN 0264-3294

Vuilleumier, P. (2000). Faces call for attention. evidence from patients with visual extinction. Neuropsychologia, Vol. 38, No.5, (2000), pp. 693-700, ISSN 0028-3932

Wada, Y. \& Yamamoto, T. (2001). Selective impairment of facial recognition due to a haematoma restricted to the right fusiform and lateral occipital region. Journal of Neurology, Neurosurgery, and Psychiatry, Vol.71, No.2, (August 2001), pp. 254-257, ISSN 0022-3050

Watanabe, S.; Kakigi, R.; Koyama, S. \& Kirino E. (1999). Human face perception traced by magneto- and electro-encephalography. Cognitive Brain Research, Vol.8, No.2, (July 1999), pp. 125-142, ISSN 0926-6410

Wilson, FA.; Scalaidhe, SP. \& Goldman-Rakic, PS. (1993). Dissociation of object and spatial processing domains in primate prefrontal cortex. Science, Vol.5116, No.260, (Junuary 1993), pp. 1955-1958, ISSN 0193-4511

Winston, JS.; Strange, BA.; O'Doherty, J. \& Dolan, RJ. (2002). Automatic and intentional brain responses during evaluation of trustworthiness of faces. Nature Neuroscience, Vol.5, No.3, (March 2002), pp. 277-283, ISSN 1097-6256

Wolwer, W.; Streit, M.; Polzer, U. \& Gaebel, W. (1996). Facial affect recognition in the course of schizophrenia. European Archives of Psychiatry and Clinical Neuroscience, Vol.246, No.3, (1996), pp165-70., ISSN 0940-1334 
Wright, IC.; Rabe-Hesketh, S.; Woodruff, PW.; David, AS.; Murray, RM. \& Bullmore, ET. (2000). Meta-analysis of regional brain volumes in schizophrenia. The American Journal of Psychiatry, Vol.157, No.1, (January 2000), pp. 16-25, ISSN 0002-953X

Yeap, S.; Kelly, SP.; Sehatpour, P.; Magno, E.; Javitt, DC.; Garavan, H; Thakore, JH. \& Foxe, JJ. (2006). Early visual sensory deficits as endophenotypes for schizophrenia. highdensity electrical mapping in clinically unaffected first-degree relatives. Archives of General Psychiatry, Vol.63, No.11, (November 2006), pp. 1180-1188, ISSN 0003-990X 


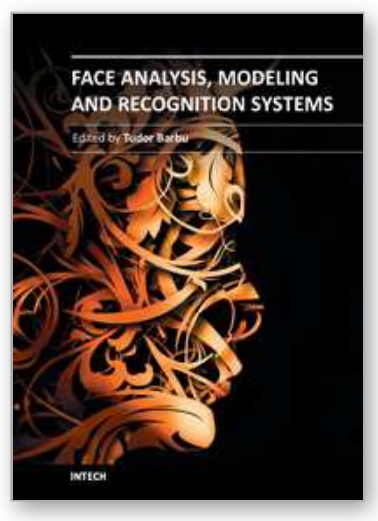

\author{
Face Analysis, Modeling and Recognition Systems \\ Edited by Dr. Tudor Barbu
}

ISBN 978-953-307-738-3

Hard cover, 212 pages

Publisher InTech

Published online 30, September, 2011

Published in print edition September, 2011

The purpose of this book, entitled Face Analysis, Modeling and Recognition Systems is to provide a concise and comprehensive coverage of artificial face recognition domain across four major areas of interest:

biometrics, robotics, image databases and cognitive models. Our book aims to provide the reader with current state-of-the-art in these domains. The book is composed of 12 chapters which are grouped in four sections. The chapters in this book describe numerous novel face analysis techniques and approach many unsolved issues. The authors who contributed to this book work as professors and researchers at important institutions across the globe, and are recognized experts in the scientific fields approached here. The topics in this book cover a wide range of issues related to face analysis and here are offered many solutions to open issues. We anticipate that this book will be of special interest to researchers and academics interested in computer vision, biometrics, image processing, pattern recognition and medical diagnosis.

\title{
How to reference
}

In order to correctly reference this scholarly work, feel free to copy and paste the following:

Toshiaki Onitsuka, Tomoya Tsunoda and Naotoshi Ohara (2011). New Findings for Face Processing Deficits in the Mental Disorder of Schizophrenia, Face Analysis, Modeling and Recognition Systems, Dr. Tudor Barbu (Ed.), ISBN: 978-953-307-738-3, InTech, Available from: http://www.intechopen.com/books/face-analysismodeling-and-recognition-systems/new-findings-for-face-processing-deficits-in-the-mental-disorder-ofschizophrenia

\section{INTECH}

open science | open minds

\section{InTech Europe}

University Campus STeP Ri

Slavka Krautzeka 83/A

51000 Rijeka, Croatia

Phone: +385 (51) 770447

Fax: +385 (51) 686166

www.intechopen.com

\section{InTech China}

Unit 405, Office Block, Hotel Equatorial Shanghai

No.65, Yan An Road (West), Shanghai, 200040, China

中国上海市延安西路65号上海国际贵都大饭店办公楼405单元

Phone: +86-21-62489820

Fax: $+86-21-62489821$ 
(C) 2011 The Author(s). Licensee IntechOpen. This chapter is distributed under the terms of the Creative Commons Attribution-NonCommercialShareAlike-3.0 License, which permits use, distribution and reproduction for non-commercial purposes, provided the original is properly cited and derivative works building on this content are distributed under the same license. 